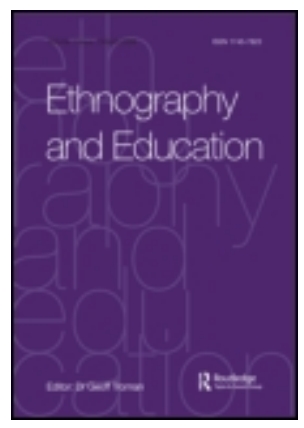

\title{
Drawing Relationally for an Ethnography of Practice
}

\begin{tabular}{|r|l|}
\hline Journal: & Ethnography and Education \\
\hline Manuscript ID & REAE-2019-0035.R4 \\
\hline Manuscript Type: & Special Issue Article \\
\hline Keywords: & art-based, methodology, relational, drawing, sociomaterial \\
\hline \multicolumn{2}{|l}{} \\
\end{tabular}

\section{SCHOLARONE ${ }^{\text {Th }}$ \\ Manuscripts}

This is an Accepted Manuscript of an article published by Taylor \& Francis Group in Ethnography and Education on 14 Mar 2020, available online http://www.tandfonline.com/10.1080/17457823.2020.1739544. 


\title{
Drawing Relationally for an Ethnography of Practice
}

\author{
Maureen K. Michael
}

Faculty of Social Sciences, University of Stirling, Stirling, United Kingdom

m.k.michael@stir.ac.uk

$+44(0) 17866135$

ORCID 0000-0001-7538-7084 


\begin{abstract}
Education ethnographies show that observing bodies, objects and settings can illuminate previously hidden learning practices but the relational characteristics of these practices presents methodological challenges for conventional qualitative analyses. Using an example from an ethnographic study of everyday learning, I show how methods from art (specifically researcher-created drawings) can address some of these challenges. I use the concept of 'epistemic objects' to theorise drawings as analysis, and to show that rather than being a process of deconstruction, this analysis is constantly bringing knowledge into being. With original interdisciplinary insights from art/social science this article problematizes art in sociomaterial research and offers direction for relational analyses.
\end{abstract}

Keywords

art-based, drawing, methodology, relational, sociomaterial 


\section{Introduction}

With the dense black ink of a fine-nibbed pen, I made three small drawings and considered them analyses. Aesthetically, I never liked these drawings, but I found them extraordinary for the analysis they made possible in an ethnographic study of practices. The analysis made by the drawings is the focus of this article. My central purpose with this article is to share an analytic technique of drawing and my aesthetic experience of doing so. I want to explain how the act of drawing and its product (the drawings), performed a relational form of analysis; and to explain the underpinning theoretical concepts. Whilst many ethnographic studies use drawing as data collection, few claim drawings as analysis, and fewer still explain how the drawing-as-analysis works. The empirical context for my drawings was an ethnographic study of artists. In the original study I had turned to drawing when conventional category-based analyses would not 'work' with the particular persuasion of my theoretical framework - a sociomaterial framework - for exploring the entanglement of the social and the material in the construction of practices (relational rather than one distinct from the other). The sociomaterial persuasion was problematic for analytic tools that depended on deconstructing things into codes and categories. It was my desire to preserve the entanglement that led me to appeal to my expertise as an artist and art educator; to analyse relationally using drawing.

The structure of this article is as follows. I begin by describing drawing as already familiar to ethnography and offer some examples. This is followed by explanations of key visual elements used in drawings (lines, shapes and composition); and I propose that a practical understanding of each offers a means of operationalising three relational concepts underpinning my ethnographic and artistic approaches: practice, materiality and knowing. A brief explanation of these concepts signposts their methodological challenges, namely preserving the all-in-oneness and then showing how 
this is the case. Then, referring to photographs, fieldnotes and interview transcripts, I present the empirical focus for analysis - an ethnographic account of practices hidden in a lunchtime routine in the everyday work of a conceptual artist This account provides the context for the visual heart of this article - three drawings - and I explain how the visual elements in the drawings did their work as mediators of a process of analysis, how they revealed the previously hidden practices. I then discuss the concept of 'epistemic objects' to theorise drawings as analysis, showing that rather than being a process of deconstruction, this analysis is constantly bringing knowledge into being. I conclude the article with a summary of the main argument: drawing (and drawings), theorised as an epistemic object offers a rationale for taking drawing seriously as relational analysis. The conclusion points to the implications for research education, with a reminder to those using drawing as analysis in relational research that they should be ready to explain how art does its work - and in this way open their analysis to critique in order that others might learn.

\section{Drawing and Visual Elements}

Drawing is the art of representing by line, the contours of a thing, real or imagined. Already familiar to ethnography, such representations are 'fundamental to being human' and, as a technique of observation, drawing is 'unrivalled' says Ingold (2010 177, 179). Drawing is a 'means of translation, documentation and analysis' (Clarke and Foster 2012, 2); an observational resource for ethnographers (see for example, the ethnographic field drawings of Wettstein [2011]); and in the work of Heath, Chapman and The Morgan Sketchers (2018), drawing (a term they use interchangeably with 'sketching') is a means of recording in-situ observations of urban life, affording insights unlikely through photography. For example, they describe how sketching in real time means they are often recording 'extended moments of time in one 
single image, unlike the faction of a second represented in a photograph' and that a habit of annotating the sketches with notes about sounds, smells, weather and feelings etc means that the circumstances of the sketching production become inscribed not only in memory but in the visual record of observation (Heath et al 2018, 120). Certainly, drawing offers ethnographic possibilities as fieldwork documentation, illustration, reflection and member-checking (Kuschnir 2016). However, the drawings themselves are not problematized beyond the means of production: their visual language claimed as 'much more accessible than written texts' (Kuschnir 2006, 127) thus seldomly explained. In other words, how the drawings document, illustrate or otherwise is left without explanation. For example, what is it about the pencil and the paper that creates the 'sketchiness' important to Heath et al's (2018) documentation? What is it about the physical acts of looking/drawing/looking/drawing with pencil and paper that document not just an observation but a multi-sensory memory of the observation? The materials involved in the construction of the drawing, along with its composition of lines and shapes, have much to tell us about the interactions amongst the things documented - if only we knew how to understand what the drawings are saying. Why is this important? Research on the relational material practices of learning has raised methodological challenges, not least the analytical tendency towards deconstruction. My experience is that drawings both constitute relational practices and have the capacity to analyse their all-in-oneness. My experience as an artist and education researcher is that drawings present a useful material counterpoint to what Tummons and Beach $(2019,3)$ describe as the 'the emergence of anthropocentrism (that is, human-centredness in data construction, analysis and theorisation) in ethnography'. However, to know what the drawings are saying, we must first accept that they have that agential capacity, that they can make themselves understood. To help in this regard, I turn to the field of art. It is 
from the perspectives of art, artists and art education that we might understand drawings from a perspective of the visual and aesthetic elements that create them. This perspective is less a framework for how to do art-based analysis, and more a reference point that takes forward the problem of art as an analytic resource in relational research (Rousell 2019).

In art (and art education) there are many varied definitions of drawing (Ashwin 2016). From an artist's perspective, drawing is not only a way to describe what they see but it is also the actual means of seeing (Lyons 2012); or in other words, an investigative act of looking (Petherbridge 2008) and thus a way of understanding what they see (Farthing 2009). Drawing is both a process of discovery (Berger 2005) and a record of that process. The purpose of drawing in this sense is to understand. The act of drawing can refer to sketching, quick rendering of an object's form (or equally, of a person or place - as in Lynne Chapman's outdoor sketches discussed in Heath et al (2018)). But this act can also refer to slower, more careful studies that describe the detail of a given form - as in the anatomical drawings. The process of drawing (drawing as a verb) involves an on-going action of visual understanding. Drawing, as a noun, is the conclusion of that process - a product inscribed with visual understanding. Anatomical drawings are fair examples of how purpose, process and product combine. Reflecting detailed observation (investigative acts of looking) anatomical drawings illustrate detailed understanding of the human body (Sawchuck, Woolridge and Jenkinson 2011). The lines (and colours) of anatomical drawings describe knowledge of the human body. Lines could be heavy, bold, and most likely in black - delineating the edge of an organ, the length of a vein, the striations of a muscle. The lines offer a boundary and the boundary describes a shape. But equally, the lines might be lighter, leaner, appearing less black - describing a comparative fragility, thinness or smallness. 
And these lighter, leaner lines might be 'cross-hatched', layered on top of each other, first in one direction then the next, creating depth and shadow, showing bounded shapes now as three-dimensional forms that overlap and shift in the volume of the body. Compositions of lines and shapes, bring the anatomical understanding into being, they produce knowledge. In effect, says McGuirk (2011) drawings produce knowledge. Not all drawings are as pedagogical as anatomy drawings but they all depend on visual elements to communicate.

Lines, shapes and composition are thus visual elements that explain the work of drawing and how drawings produce knowledge. Understanding their functions gives us a vocabulary to explain how a drawing 'works'. Lines are marks that express the linear contours of a thing, real or imagined; they have the capacity to set one thing as distinct from another - and in this regard, lines can be descriptive. Shapes however, recognise the mass of a real or imagined thing, recognised in figurative, geometric or abstract terms (e.g. table, rectangle, energy). Composition is the arrangement of lines and shapes within the boundaries of a given surface (e.g. a piece of paper or screen). Lines, shapes and composition make sense in relation to each other: lines define shapes; compositions need lines and/or shapes in combination on a page/surface. These visual elements are central in art but to explain their relational resonance I look to ideas borne out of art education.

Eisner (1991, 2002, 2008), a leader in art education, explains that experiences of art, aesthetic experiences, teach ways of understanding relationally: how satisfying relationships amongst parts create a 'whole'; how materials mediate aims and choices; the importance of disregarding prescribed labels and functions, instead framing the world from an aesthetic perspective; the importance of being open to change and being able to redefine options as others emerge; and the importance of the imagination, the 
interplay of human and material in order to think otherwise, beyond what first seems present. Such are Eisner's habits of art and, despite critique of their cognitive humancentric leanings (Jagodzinski and Wallin 2013), their relational underpinnings resonate with the idea of practice as materially-mediated and performed into being; defying prelabelling and being known in advance. Drawing is proposed as an appropriate method of sociomaterial analysis because not only is it entirely mediated by the materials of its construction but it inseparable from them. Whilst the same might be said for any analytic method, with drawing meaning comes not from words written in fieldnotes or spoken in interview audio but from the wordless interactions of lines, shapes and composition; interpreted through relational habits of all-in-oneness, mediating materials, disregard for labels, flexible purposing and imagination. Attuned to its own sociomaterial characteristics, drawing (and drawings) present plausible means of analysing practices.

The freehand sketching from life of the Morgan Sketchers (Heath et al 2018), or the precise anatomical drawings explored by Sawchuck, Woolridge and Jenkinson (2011) seem magical in their creation, but the type of drawing I propose here has no mystery; it is traced over a photograph. The tracing process is described later, but as sociomaterial analysis, drawing finds support in Hopwood's (2014) analysis of partnership healthcare practices. In preparing for participant interviews Hopwood traced line drawings over video stills reasoning that the drawings (tracings) avoided the sensory overload of video data and helped 'slow down' the participants' reflections during interviews. Reflecting on the usefulness of the line drawings however, Hopwood (2013 no page) in his blog explained the drawings as 'quite uninteresting' but it was their capacity to 'make connections between bodies, things and practices', scrutinising the whole, was their analytic value. In the process of discussing the 
tracings with participants, Hopwood came to recognise how the traced lines and shapes constructed relationships rather than individual people, connecting activity with the physical things involved. 'Uninteresting' seems an unfair assessment given the complexity of such construction, but I recognise this reaction. Hopwood made his tracings to interrupt the smooth storying presented by video and draw attention to the fact that an interruption had taken place. Thus, his decision to eschew video stills for hand-drawn tracings. With these tracings and their incomplete rendering of people and things, Hopwood discovered that his interview participants were more readily disposed to ask questions about missing objects and dialogue - thus offering insights that the seductively smooth visual narrative of the video denied.

Influenced by earlier work (Michael 2012, 2013) Hopwood concluded his reflections through the lens of Knorr Cetina's $(1997,2001)$ 'epistemic object'. Knorr Cetina's epistemic objects make sense of how certain objects become objects of knowledge; how they gather expertise around them; and how, in that gathering they affect change - but more of that later. First, I wish to describe three interconnected concepts underpinning my ethnographic and artistic approaches: practice, materiality and knowing.

\section{Practice, Materiality and Knowing}

Many theoretical approaches might be described as sociomaterial (e.g. actornetwork theory; complexity; cultural historical activity theory) each with distinctive orientations but what they share is a focus on materials as entangled with everyday practices (Fenwick, Edwards and Sawchuk 2011). A focus on practice is a useful entry point to the meaning of sociomaterial.

Practice theory is not a single unified theory (Schatzki 2001) but a family of theories with shared traits related to action, materiality and context (Reckwitz 2002). 
First, practices are the doing of social life: they are physical accomplishments otherwise known as enactments. Second, practices are materially mediated: they are accomplished with the participation of objects, technologies, and settings etc. Third, practices are situated: essential characteristics of a given practice are context, setting and place. These descriptions bring together the interrelationships of the social and material aspects of practice denoting what Fenwick, Edwards and Sawchuck (2011) describe as a sociomaterial sensibility - a relational attunement to the infusion of materials in everyday practices. With this sensibility learning is understood as shaped by materiality (Sorensen 2009) and an embodied effect of practices. Learning is not transferred from one mind to another, rather it is a consequence of the material entanglements of practice. Theoretical resources such as Gherardi's (2001) knowing-inpractice help make sense of the relationship between learning and material practices. However, Knorr Cetina's $(1997,2001)$ epistemic objects makes sense of how certain objects become objects of knowledge; to make sense of how they gather expertise around them; and how, in that gathering they affect change. A defining characteristic of an epistemic object is its openness to change: it is always left wanting. Significantly, Knorr Cetina, attentive to the emotional work of epistemic objects, describes the dissociative dynamic that occurs when knowledge is 'looped through' objects - a dynamic that sustains practices despite their emotional costs. These critical theoretical constructs challenge the idea that learning is located solely in the mind. Instead they construct learning as an effect of bodies, objects, tools, technologies and settings assembling together as practices (Fenwick 2012). Such are the characteristics of a sociomaterial disposition towards practice and learning. The term 'sociomaterial' is descriptive of a theoretical disposition that embraces, with even measure, the social and material aspects of practice and learning (Fenwick and Edwards 2010), or in the words 
of Orlikowski $(2007,1437)$ 'there is no social that is not also material, and no material that is not also social'.

What does this sociomaterial disposition mean for an ethnography of practice? In his analysis of the materiality of the classroom Roehl (2012) explains that ethnography, with its capacity to open situated knowledge to view, is well suited to the pursuit of material practices: direct observation of objects (including people) and settings remains a central method for sociomaterial studies. With many variations, a central concern with a sociomaterial approach to ethnography is operationalising relational concepts (Fenwick et al, 2014). For this article, a sociomaterial approach to ethnography means direct observation of material things (i.e. objects, technologies and settings) in ways at least equivalent to those that notice people. It does not mean observing first what a person is doing (e.g. eating) then the things involved (e.g. soup, spoon, table, etc.). Rather, it means observing the togetherness of this and finding a way of preserving the togetherness, or its relationality (for example, eating with the spoon in the kitchen); it is about finding a way of making sense of this togetherness without deconstructing it. Which brings me to what a sociomaterial disposition means for analysis: what concept is capable of keeping things together? In theoretical terms, what is needed is an appropriate gathering metaphor that makes sense of the interrelationship of practice, materials and learning. Assemblage, as theorised by Law (2004) is particularly useful. Law describes assemblage as
a process of bundling, of assembling, or better of recursive self-assembling in which the elements put together are not fixed in shape, do not belong to a larger pre-given list but are constructed at least in part as they are entangled together (Law 2004, 42).

The elements put together, in the example for this article, are the foods, objects and activities of a lunchtime routine. Regarding each of these without privilege over 
another, without predetermining its relationship invokes Latour's (2005) concept of symmetry. Incorporating assemblage and symmetry into the theoretical framework discourages an a priori analysis, thus aligning the sociomaterial concepts with those of art. Just as a drawing cannot be fully known in advance, then so it is with practice, materiality and knowing. The assemblage cannot be known in advance because by its very nature it is always in the process of becoming. Therefore, sociomaterial analysis, like drawing, seeks to understand the processes of becoming, of understanding the whole in relation to the constituent parts, whilst at the same time, again like a drawing, the analysis is both the result of, and the process of understanding.

In methodological terms, the 'how' of a sociomaterial empirical study is noted by Gherardi (2017), a leader in the field, as 'still open and crucial'. Reflecting on three different object-oriented approaches, Fenwick et al (2015) observe how sociomaterial concepts are difficult to operationalize in existing qualitative terms, and observed that whilst many sociomaterial studies are able to state that a practice is sociomaterial, conspicuously less have ventured to show how (Fenwick 2010). Decuypere and Simons' (2016) answer to this is a way of seeing informed by mathematical principles of objects, space and time - a social topology - that affords relational expressions to figures and forms. Sociomaterial modes of analysis need to be capable of preserving the relational nature of practices as enacted, materially mediated, and situated; they need to be able to analyse the all-in-one-ness of practices in a way that does not fix or lose their dynamic, changing nature. What is needed are analytic methods with predilections towards simultaneous composition, analysis and interpretation, or in other words, through methods related to art.

\section{Everyday Learning...and Lunchtime}

To illustrate the analysis, I have selected an empirical example from a larger 
ethnographic study of everyday learning in conceptual art (Michael 2018). The larger study took place over a period of 18 months where I observed three female and two male artists working variously as filmmakers, photographers and printmakers in the same European city. All five are alumni of the same art school, with respective international reputations in the field of conceptual art $\mathrm{i}^{\mathrm{i}}$. Arranging my time across all five artists, I followed each one as they travelled between studios, specialist workshops, galleries and home. I accompanied them as they met with curators, collaborators and family members. I worked alongside them editing digital film and making film-props, assisting with dark-room photograph, and preparing inks for screen-printing, etc. I came to know that dog-walking and deli-visits are as vital a part of an artist's day as filmmaking and exhibition openings. During this period, I created a total of 2,702 digital photographs ${ }^{\mathrm{ii}}$; undertook four 2-hour individual photo-elicitation interviews (Harper 2002); created five photocollages; and drew 22 individual line drawings. For the purposes of this article however, I have selected observations of the lunchtime routine for the artist Roddy, and three of the line-drawings to provide the specific analytic examples (Fig 3-5).

During an intensive period of six months I observed Roddy at work in his studio, taking 236 photographs of the activities and objects involved. As I looked across a series of photographs depicting his lunchtime routine, I wondered what the objects were 'doing' to keep this routine in place - a routine of unexpected importance.

Roddy is a full-time conceptual artist working with video, film and photography. His studio, located in a tenement apartment in the city, is composed of four rooms: office; production room (technology for editing film); archive (storage of art), and kitchen. The period of fieldwork coincided with an unintended extended episode of downtime. 


\section{Lunchtime}

At about 12.30pm Roddy stops working at his computer, changes into outdoor shoes, leaves his studio and walks to a nearby delicatessen. He follows the same fiveminute route each time. Roddy approaches the deli counter smiling and says to the assistant "This is Maureen, and she is taking photographs of me. Is it ok if she takes photographs of me buying my soup?". He tells her the photographs are for his parole officers as proof of where he goes at lunchtimes.

“Are you joking?" she asks.

"I'm not joking that someone is taking photographs of me, but yes, I am joking about the parole".

He buys minestrone soup, two bread rolls and a slice of millionaire's shortbread. As we walk back to the studio, we meet the postman who delivered Roddy's mail - now retired - and we chat for a few minutes.

Returned to the studio, Roddy changes his shoes, takes the soup, bread and shortbread into the tiny kitchen, placing them on the compact table with a mug. He sits at the table. In front of him, amongst all of these objects, is a book held open with two ornate candlesticks. The book concerns a topic close to his artistic concerns; he describes his choice of lunchtime reading as,

the more difficult books, you know, the ones that are not appealing to read but you want to cover for research purposes (Fieldnotes 08 Jan 2013, p.13)

Roddy reads the book, his hands freed by the candlesticks, and eats the soup and bread. He continues to read until all is eaten. The routine of deli, lunch and reading takes an hour, after which Roddy returns to his office and computer. 
The photograph below (Fig 1) shows the kitchen table, and is significant because Roddy identified representative of his then current everyday work (selecting it from the 25 used in my interviews with him).

- Insert Figure 1 here -

I am struck by the monastic aesthetic of the table. Incongruous things carefully arranged, appear as if in a still-life, evoking a sacred ritual. The still-life intrigues me. Look at the crumpled paper bag slowly unfurling - seconds ago released from Roddy's grip; the empty mug awaiting tea; the salt and pepper ready to season the soup.

Although 'still' the scene is full of movement, and whilst Roddy is not depicted, his actions are evident. I know the photograph is not the actual observation; it is not the actual hiatus; that it only 'stands in for' these. However, like the words in a transcript or a fieldnote page, it is part of what constitutes my analysis. The photograph has flattened everything onto a single plane. Shadows suggest depth but the physical flatness of the photograph affords equal value to the objects - each as flat as the other. However, this is not the photograph I choose to trace. My attention has been captured by the blue of a knitted sweater 'glowing' (McLure 2013) in the foreground of another photograph from the photo-elicitation set of 25. This is the photograph I decide to trace (Fig 2).

- $\quad$ Insert Figure 2 here -

\section{Drawing Relationally}

Tracing the contours of a person, of things, is an intimate process. It involves looking through translucent paper to a photograph beneath, deciding what to trace and how. The first drawing (Fig 3) is tight, meaning the lines adhere closely to the photograph below.

- $\quad$ Insert Figure 3 here - 
I trace the detail of nearly every object (e.g. hair, ridges on the candlesticks). I trace the contours of everything but wonder if 'everything' is necessary. The purpose of the drawing is not to replicate the photograph but to investigate its detail; to discern forms, connections and relationships. However, at this early stage, tracing a line around each object is instructive. I let the lines teach me the boundary of a form, giving shape to its distinctiveness - that which sets it apart. In order to draw the lines, I must decide the direction of each, thinking of the shapes they are creating and the forms they are suggesting. But this is problematic because the separation of objects seems disloyal to sociomaterial values and as their assemblage is my analytic interest, I wonder what is necessary to show this. I trust I will find out with subsequent iterations.

In the second drawing (Fig 4) I trace again the outlines but I become less interested in their internal detail. It seems unnecessary to include the detail in Roddy's hair - it a few short lines are all that is needed; similarly, in the ridge-detail of the candlesticks - a line around their outline seems enough.

- $\quad$ Insert Figure 4 here -

This second drawing still describes individual objects but fewer lines are involved in the description. Notice the absence of a line defining the edge of the kitchen table previously separating Roddy from the other objects. The absence creates a new shape: a new relationship is brought into view. The table has not vanished but the relationship amongst all the objects (including Roddy) is understood differently. Additionally, without a frame to the drawing, the white shapes merge beyond the scene, beyond what is immediately apparent. In analysing the lines, shapes, forms and composition, relational possibilities are revealed. 
In starting the third, final drawing of this series (Fig 5) I decide whether to trace a line completing the ellipsis of the soup cup (thereby defining a distinct object), or to continue the line to include the book, candlesticks and cup as a single form.

- Insert Figure 5 here -

I make the decision to trace around all three and although the overall outline has remained the same (as Fig 4), the balance of lines and shapes is different. There are fewer lines. In fact, there are now only two lines: the shapes that they bind no longer stand in for discrete objects. Incomplete shapes take on significance precisely because they are no longer specific objects. The composition of lines and shapes blurs distinctions between actions and objects. White shapes morph from one to the next, disrupting the presumption of a boundary, suggesting the on-going assembling. The drawing confronts me with an incomplete and on-going stillness - a pause. I arrive at the 'pause' through the visual thinking deliberately looped through drawings and the reaction granted by them.

I propose each drawing as synonymous with analysis and, through Knorr Cetina, I propose to conceptualise each as an epistemic object: open-ended, inviting and generating questions, not finished or complete. This seems a useful way to understand how the art vocabulary of unfinished lines, abstract shapes and unbounded composition acted together to interrupt my habitual way of thinking both about drawings and analysis. As an epistemic object the drawings are in a constant state of being materially defined and always serving as a line of inquiry for further analysis. Each drawing, as an object of knowledge is never fully attained 'they are if you wish, never quite themselves' (Knorr Cetina, 2001, 181). The drawing is defined in part by absence, by what it is not. The analysis it is yet to be will unfold. As it unfolds, the drawing exists in the form of photographs, paper, ink and lines, etc - what Knorr Cetina (2001) calls 
instantiations - partial objects in relation to the whole. The photographs, paper etc are not preparatory of the analysis, they are the analysis, as it unfolds. The drawing of Figure 1, despite its intermediary stage still constitutes the analysis. Even when the drawing is declared finished (for example, when a subsequent drawing is started), the analysis of the first drawing is subject to what it could have become and did not. Both the drawing and the analysis are incomplete but they are no less imbued with the knowledge of practice (the practice of pause). Further, attentive to the emotional work of epistemic objects, Knorr Cetina describes the dissociative dynamic that occurs when knowledge is 'looped through' objects - a distancing between self and knowledge something I recognise when I create drawings as analysis - knowledge is 'looped through' the drawings and they become both the process of analysis and at the same time, a visual statement of the knowing. Thought of as an epistemic object then each drawing makes sense as analysis. And, rather than being a process of deconstruction, this analysis is constantly bringing knowledge into being.

Despite this however, the analysis is problematic. The visual language of the drawings is a barrier if understanding is preoccupied with analysing texts and textual representations - the dominant preoccupation of qualitative analyses. Additionally, the fixed nature of the compositions betrays the fluidity and polysemy of the analysis they represent. To help with these two concerns I return to the habits of art (Eisner 2002). Framed by art's aesthetic perspective then the compositions are open to redefinition as new interpretations emerge. As this perspective disregards labels and functions then the language barrier can be overcome. What is required is a willingness to think differently about the language of analysis, to think differently about language.

These drawings show, not a practice, but a practice being analysed, and are themselves objects around which knowledge is constructed. These instructive drawings 
teach the viewer of the practice of pause. The practice of pause was co-constructed with line, shape and composition coalescing with bodies, objects and settings, albeit in a manner that is incomplete, unfinished, unsatisfying. This incompleteness characterises Knorr Cetina's epistemic objects. Just as the practice of pause is forever in a state of becoming, so it is for each 'epistemic' drawing - forever unfolding, forever in a state of becoming. The cessation of the act of drawing does not mean that the drawing is complete; indeed, the drawing is forever incomplete, it can always become more, become other. In this regard, drawings, analyses and practices mutually constitute each producing the other. The two-dimensional plane of drawing brings an even attention to the lines drawn and the relations they shape. The drawing performs the flattened ontology defining this sociomaterial approach. By showing how the drawings are constructed, and by revealing the entangled art-sociomaterial thinking of their construction, I have explained how the drawings work in the analysis.

\section{Conclusion}

The central argument of this article is that theorising drawing as an epistemic object offers a rationale for art-based approaches to analysis for ethnographic studies of sociomaterial practices. This theorising is important because it addresses one of the key methodological challenges with relational approaches to the study of practice, namely how to analyse practices in ways that resist conventional tendencies towards deconstruction and instead preserve the characteristic all-in-oneness of relational practices. I have made this argument by paying attention to the process of drawing and to my aesthetic experience of this process. Through explaining the tracing method of drawing I have shown how a vocabulary of lines, shapes and composition can show relations incommensurate with word-based categorisations, and depict the combined social and material constituents of a practice. Further, in 'drawing out' the construction 
of one such practice I have pointed to drawings as epistemic objects (Knorr Cetina 1997) and their knowledge-creating analyses. But I have also shown how this analytic vocabulary is problematic: in their default to delineation, lines are susceptible to fixing a single description; to containing and ordering - betraying the fluidity of the analysis they construct. Whilst all methods have their limitations, a solution for this present context is to become literate in the intersections of drawing methods and relational concepts, to become more engaged in art theory and develop relational visual literacies. Essentially, this is a literacy that would make the language of analysis differently. Thus, sociomaterial researchers could be, as Rousell (2019) suggests, ready to explain how art does its work in research - and thus more able to critically engage with and re-present, defaulting singular interpretations. This is an interdisciplinary solution that presents interesting conundrums for the professional education of researchers, i.e. how best to develop such expertise, and how best to teach it, in academic fields that remain predominantly discipline-based and fixated to analysing texts and textual representations. This article is a contribution in this regard.

Whilst earlier sociomaterial studies reported methodological challenges, this article, by illustrating and exemplifying the analytical use of drawing, is amongst the first to respond with a detailed account of how the art and relational concepts work together. The article is both ethnographic and educational in this respect: providing a detailed account of operationalising art and relational concepts; and showing how to overcome methodological challenges through aesthetic visual skills and concepts. Drawing relationally is not about being an artist, it is being open to the materialities and aesthetics of analysis in ethnography of education. 


\section{Acknowledgements}

The wider ethnographic study contextualising this article would not have been possible without the generosity of the participants: Claire Barclay, Roderick Buchanan, Duncan Campbell, Christina McBride and Karen L. Vaughan. Additionally, I wish to thank the anonymous reviewers for their feedback on earlier versions - hidden but essential work in academia - this article has benefited greatly from their insights.

\section{References}

Ashwin, C. 2016. "What is a Drawing?" Drawing: Research, Theory, Practice 1 (2): 197- 209.

Berger, J. 2005. Berger on Drawing. Co. Cork Ireland: Occasional Press.

Clarke, J. and Foster, K. 2012. "Field drawing and dialogue as a form of making knowledge.” TRACEY Journal May 2012. www.lboro.ac.uk/departments/sota/tracey/

Decuypère, M. and Simons M. 2016. "Relational thinking in education: topology, sociomaterial studies and figures." Pedagogy, Culture and Society 23 (3): 371386.

Eisner, E. W. 1991. The enlightened eye: Qualitative inquiry and the enhancement of educational practice. New York: Macmillan.

Eisner, E. W. 2002. Arts and the Creation of Mind. New Haven and London: Yale University.

Eisner, E. W. 2008. "Art and Knowledge" in Handbook of the Arts in Qualitative Research edited by J.G. Knowles and A. L Cole. 3-12. Thousand Oaks, CA: Sage

Farthing, S. 2009. "On drawing a man reading a newspaper", Visual Communication, 8, 147-158.

Fenwick, T. 2010. "Reading Educational Reform with Actor Network Theory: Fluid Spaces, Otherings and Ambivalences" Educational Philosophy and Theory 43(1): 114-134.

Fenwick, T. 2012. "Co-production in Practice - A Sociomaterial Analysis." Professions and Professionalism 2 (2): 1-16.

Fenwick, T., Doyle, S., Michael, M. K. and Scoles, J. 2014. "Matters of Learning and Education: Sociomaterial Approaches in Ethnographic Research." In MultiPluriTrans in Educational Ethnography: Approaching the Multimodality, Plurality and Translocality of Educational Realities, edited by S. Bollig, S. M-S. Honig, S. Neumann, and C. Seele, 141-162. Bielefeld, Germany: Transcript Verlag/Columbia University Press.

Fenwick, T. and Edwards, R. 2010. Actor-network Theory in Education. London: Routledge.

Fenwick, T., Edwards, R. and Sawchuck, P. 2011. Emerging Approaches to Educational Research. Tracing the Sociomaterial. London \& New York: Routledge.

Gherardi, S. 2001. "From Organizational Learning to Practice-based Knowing." Human Relations 54 (1): $131-139$. 
Gherardi, S. 2017. "Sociomateriality in Posthuman Practice Theory." In The Nexus of practices: Connections, Constellations and Practitioners, edited by S.Hui, E. Shove, and T. R. Schatzki, 38 - 51. London: Routledge.

Harper, D. 2002. "Talking about pictures: A case for photo-elicitation", Visual Studies, 17(2), pp.13-26.

Heath, S., Chapman, L. and The Morgan Centre Sketchers. 2018. Observational Sketching as Method, International Journal of Social Research Methodology, 21 (6): 713-728. doi: $10.1080 / 13645579.2018 .1484990$

Hopwood, N. 2013. "Ethnographic Fieldwork: Transparency, Uncertainty and What is Going on Here?" Nick Hopwood. 19 February 2013. https://nickhop.wordpress.com/2013/02/19/ethnographic-fieldworktransparency-uncertainty-and-what-is-going-on-here/\#comments

Hopwood, N. 2014. "Using Video to Trace the Embodied and Material in a Study of Health Practice." Qualitative Research Journal. 14 (2): 197-211. doi: 10.1108/QRJ-01-2013-0003

Ingold, T. 2010. Redrawing Anthropology. Aldershot, UK: Ashgate

Ingold, T. 2011. Being Alive. Essays on Movement, Knowledge and Description. Abingdon, Oxon: Routledge.

Jagodzinski, J. and Wallin, J. 2013. Arts-based Research: A Critique and a Proposal. Rotterdam: Sense Publishers.

Kuschnir, K. 2016. "Ethnographic Drawing: Eleven Benefits of using a Sketchbook for Fieldwork." Visual Ethnography. 5 (1). doi: 10.12835/ve2016.1-0060

Knorr Cetina, K. 1997. "Sociality with Objects: Social Relations in Postsocial Knowledge Societies." Theory, Culture \& Society 14 (4): 1 - 30.

Knorr Cetina, K. 2001. “Objectual Practice.” In The Practice Turn in Contemporary Theory edited by T. R. Schatzki, T. R., K. Knorr Cetina, and E. von Savigny, 175-188. London: Routledge.

Latour, B. 2005. Reassembling the Social. An Introduction to Actor-network Theory. Oxford: Oxford University Press.

Law, J. 2004. After Method. Abington, Oxonbridge: Routledge.

Lapenta, F. 2011. "Some theoretical and methodological views of photo-elicitation", in Margolis, E. and Pauwels, L. (eds.) The Sage handbook of visual methods. London: Sage, pp. 201-213.

Lyons, L. 2012. "Drawing your way into understanding", TRACEY Journal, May 2012, [Online] Available at: http//www.lboro.ac.uk/departments/soto/tracey (Accessed 31 March 2014).

McLure, M. 2013. "Researching without Representation? Language and Materiality in Post Qualitative Methodology" International Journal of Qualitative Studies in Education. doi: 10.1080/09518398.2013.788755

McGuirk, T. 2011. "Drawing and intellectualism: Contested paradigms of knowledge", Art, Design and Communication in Higher Education, 10(2), pp. 217-231.

Michael, M. K. 2012. "The things of her practice: exploring visual methods for the study of artist's work", paper presented at ProPEL International Conference Professions and professional learning in troubling times: emerging practices and transgressive knowledges, Stirling, 9-11 May.

Michael, M. K. .2013. "Visual methodology for the study of practice", paper presented at 8th International Conference on Researching Work and Learning, Stirling, 1921 June.

Michael, M. K. 2018 "Repositioning artistic practice: A sociomaterial view”, Continuing Studies in Education DOI:10.1080/0158037X.2018.1473357 
Petherbridge, D. 2012. "Nailing the Liminal: The Difficulties of Defining Drawing." In Writing on Drawing: Essays on Drawing Practice and Research, edited by S. Garner, 27-41. Bristol and Chicago: Intellect.

Reckwitz, A. 2002. "Toward a theory of social practices: A development in culturalist theorizing." European Journal of Social Theory 5 (2): 243 - 263.

Roehl, T. 2012. "Disassembling the Classroom - an Ethnographic approach to the Materiality of Education." Ethnography and Education 7 (1): 109 - 126.

Rousell, D. 2019. "Inhuman Forms of Life: On Art as a Problem for Post-qualitative Research." International Journal of Qualitative Studies in Education, doi: 10.1080/09518398.2019.1609123

Schatzki, T. R. 2001. "Introduction: Practice Theory." In The Practice Turn in Contemporary Theory edited by T. R. Schatzki, T. R., K. Knorr Cetina, and E. von Savigny, 1-14. London: Routledge.

Sorensen, E 2009. The Materiality of Learning: Technology and Knowledge in Educational Practice. New York: Cambridge University Press.

Tummons, J. and Beach, D. 2019. "Ethnography, Materiality, and the Principle of Symmetry: Problematising Anthropocentrism and Interactionalism in the Ethnography of Education." Ethnography and Education, doi:10.1080/17457823.2019.1683756.

Werner, O. and Clark, L. 1998. "Short Talk 26: Ethnographic Photographs Converted to Line Drawings" Field Methods 10(33) 54-56.

Wettstein, M. 2011. "Ethnographic Drawing: Small Notes on a Neglected Topic in Visual Anthropology."

http://www.marionwettstein.ch/ethnographicdrawing.html 
Figures

Figure 1

Caption: Kitchen Table at Lunchtime [digital photograph]. Image Credit: Author

Figure 2

Caption: Artist and the Lunchtime Hiatus [digital photograph]. Image Credit: Author

Figure 3

Caption: Drawing One [photo-traced line drawing]. Image Credit: Author

Figure 4

Caption: Drawing Two [photo-traced line drawing]. Image Credit: Author

Figure 5

Caption: Drawing Three [photo-traced line drawing]. Image Credit: Author

'The public nature of the participants' art (exhibitions, websites, and performances) and their names, meant a condition of participation was consent to relinquish anonymity: the participants own names were used throughout the original study and also, where appropriate, in this article.

ii Each individual photograph used with consent from each respective artist 


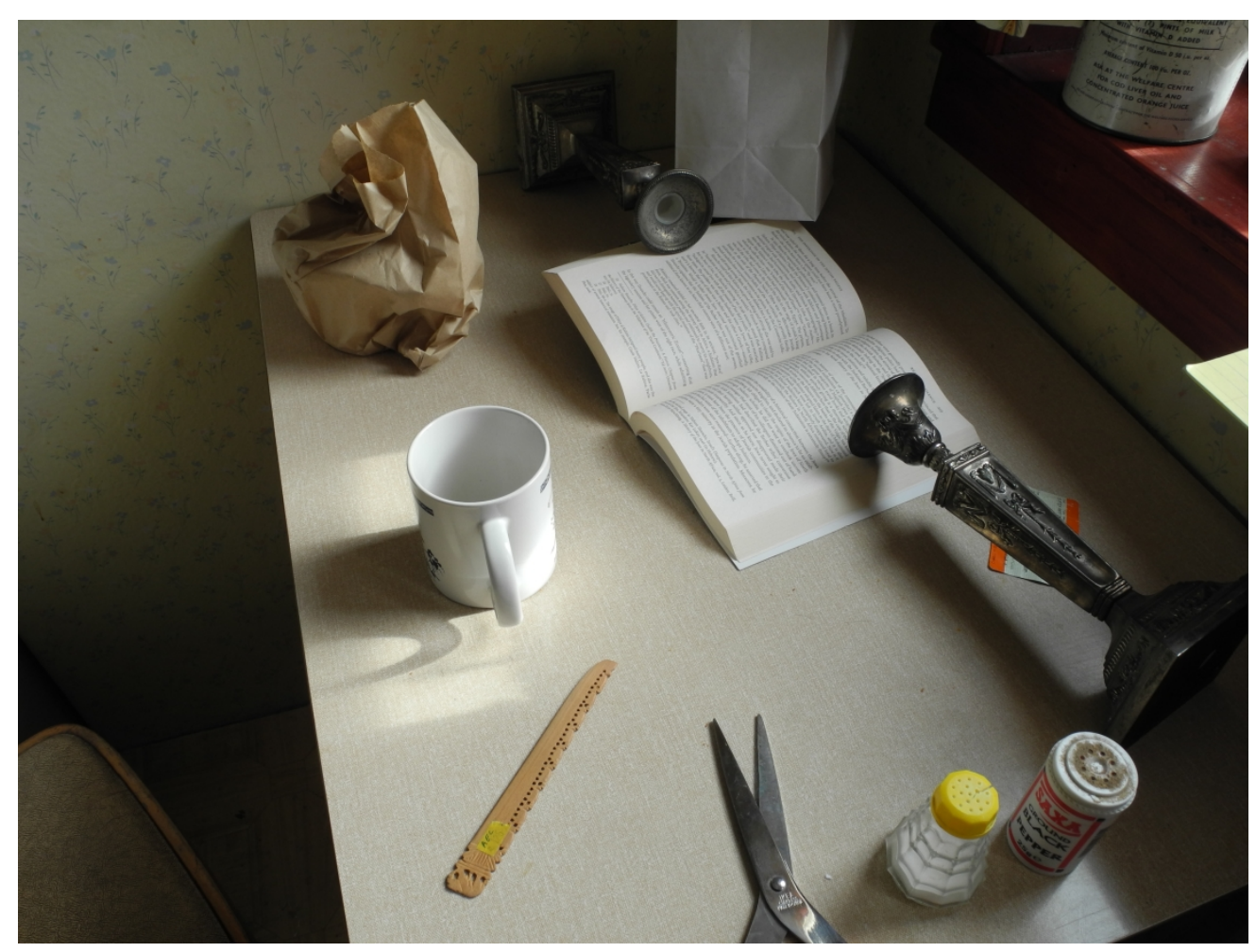

Kitchen Table at Lunchtime [digital photograph]. Image Credit: Author $308 \times 231 \mathrm{~mm}(300 \times 300 \mathrm{DPI})$ 


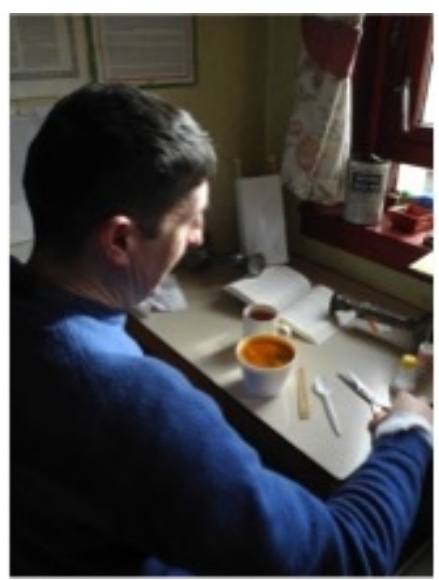

Artist and the Lunchtime Hiatus [digital photograph]. Image Credit: Author $57 \times 76 \mathrm{~mm}(72 \times 72 \mathrm{DPI})$ 


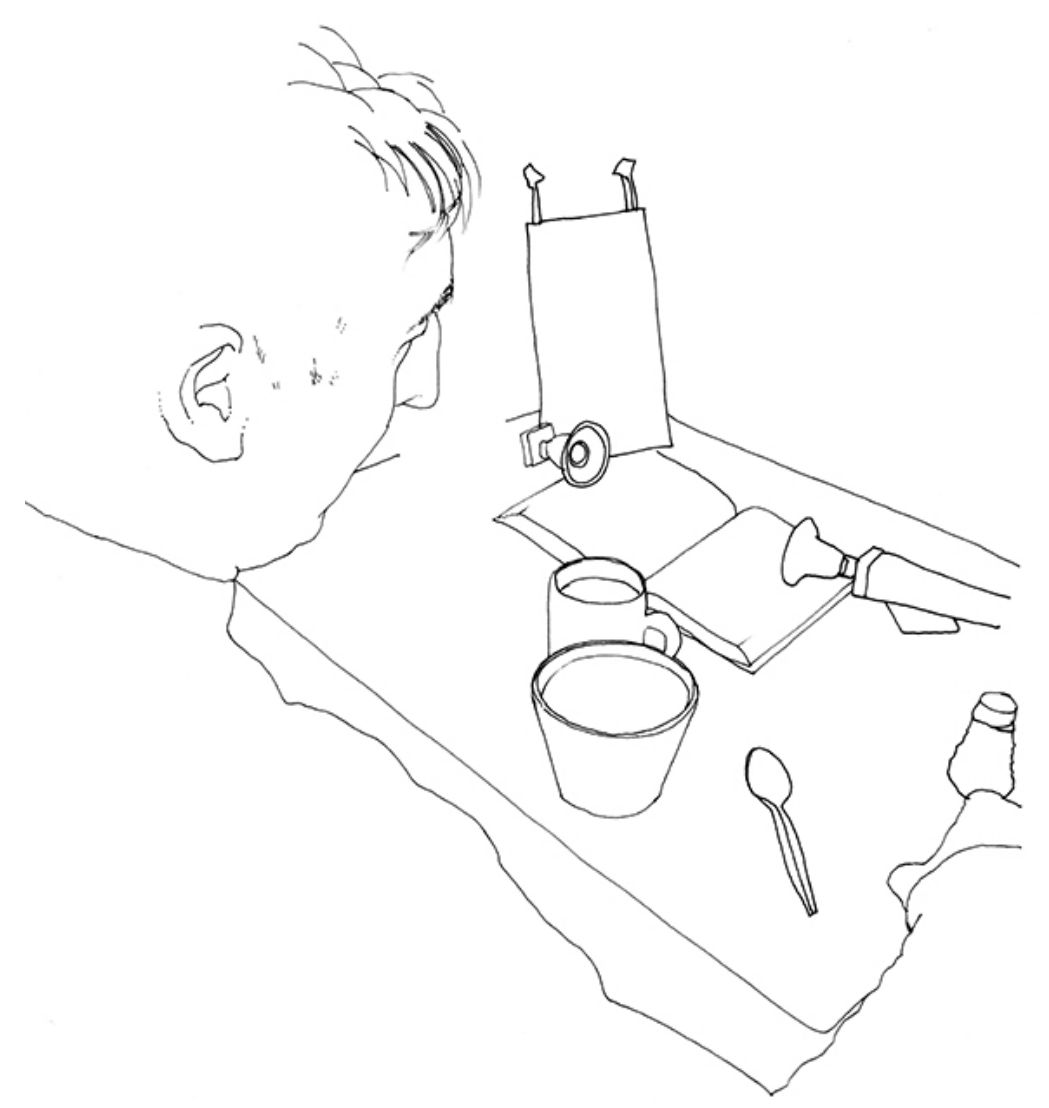

Drawing One [photo-traced line drawing. Image Credit: Author $26 \times 38 \mathrm{~mm}(600 \times 600 \mathrm{DPI})$ 


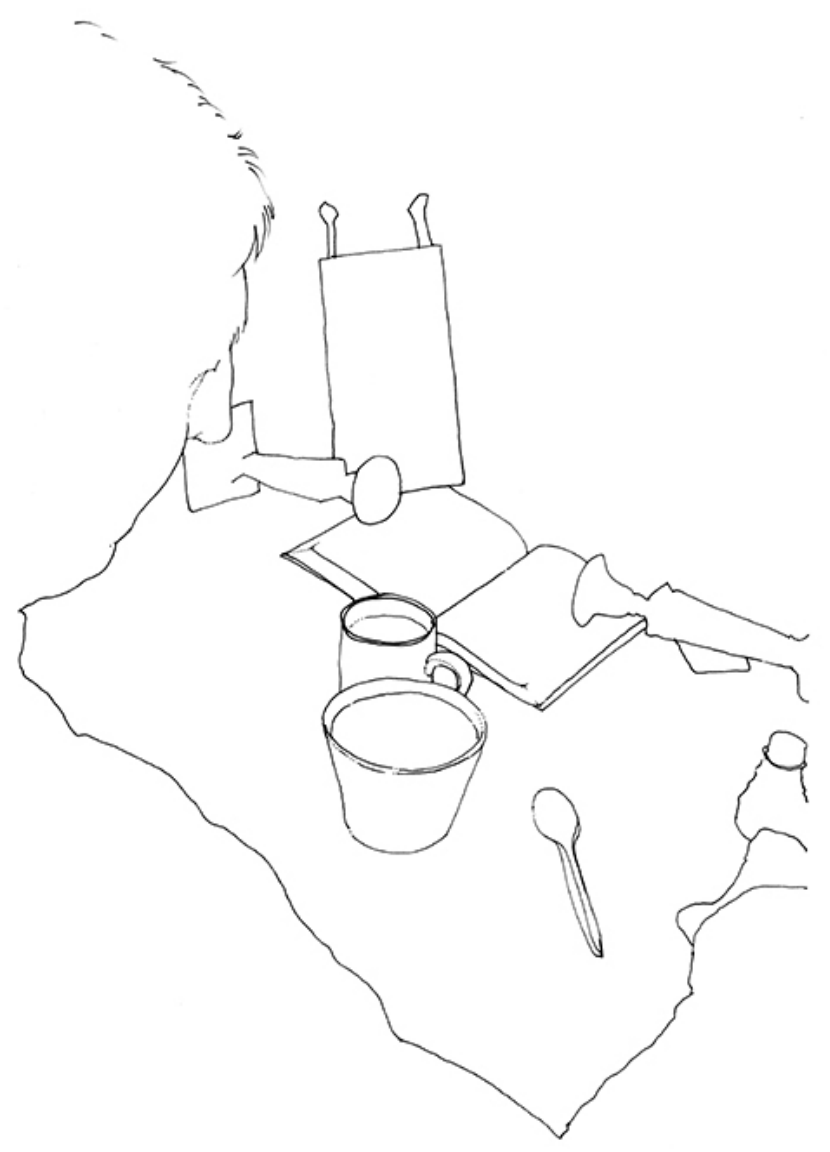

Drawing Two [photo-traced line drawing]. Image Credit: Author $26 \times 38 \mathrm{~mm}(600 \times 600 \mathrm{DPI})$ 
Drawing Three [photo-traced line drawing]. Image Credit: Author $26 \times 38 \mathrm{~mm}(600 \times 600 \mathrm{DPI})$ 